\title{
A randomised controlled trial to assess the effectiveness of a single session of nurse administered massage for short term relief of
} chronic non-malignant pain

\author{
Kate Seers*1, Nicola Crichton ${ }^{2}$, June Martin ${ }^{3}$, Katrina Coulson ${ }^{4}$ and \\ Dawn Carroll 5
}

\begin{abstract}
Address: ${ }^{1}$ RCN Research Institute, School of Health \& Social Studies, University of Warwick, Coventry, CV4 7AL, UK, ${ }^{2}$ Institute of Primary Care and Public Health, Faculty of Health and Social Care, London South Bank University, 103 Borough Road, London, SE1 0AA, UK, ${ }^{3}$ Lymphoedema Clinic, Sir Michael Sobell House, Churchill Hospital, Old Road, Headington, Oxford, OX3 7LJ, UK, ${ }^{4}$ Pain Management Department, Derby Hospitals NHS Foundation Trust, Derbyshire Royal Infirmary, London Road, Derby, DE1 2QY, UK and ${ }^{5}$ Senior Health Outcomes Manager, Sanofiaventis, Guildford, Surrey, UK

Email: Kate Seers* - kate.seers@warwick.ac.uk; Nicola Crichton - crichtnj@lsbu.ac.uk; June Martin - june.martin@orh.nhs.uk; Katrina Coulson - katrina.coulson@derbyhospitals.nhs.uk; Dawn Carroll - dawncarroll@btinternet.com

* Corresponding author
\end{abstract}

Published: 4 July 2008

BMC Nursing 2008, 7:10 doi:10.1186/1472-6955-7-10
Received: 19 December 2007

Accepted: 4 July 2008

This article is available from: http://www.biomedcentral.com/1472-6955/7//0

(c) 2008 Seers et al; licensee BioMed Central Ltd.

This is an Open Access article distributed under the terms of the Creative Commons Attribution License (http://creativecommons.org/licenses/by/2.0), which permits unrestricted use, distribution, and reproduction in any medium, provided the original work is properly cited.

\begin{abstract}
Background: Massage is increasingly used to manage chronic pain but its benefit has not been clearly established. The aim of the study is to determine the effectiveness of a single session of nurse-administered massage for the short term relief of chronic non-malignant pain and anxiety.
\end{abstract}

Methods: A randomised controlled trial design was used, in which the patients were assigned to a massage or control group. The massage group received a 15 minute manual massage and the control group a 15 minute visit to talk about their pain. Adult patients attending a pain relief unit with a diagnosis of chronic pain whose pain was described as moderate or severe were eligible for the study. An observer blind to the patients' treatment group carried out assessments immediately before (baseline), after treatment and I, 2, 3 and 4 hours later. Pain was assessed using $100 \mathrm{~mm}$ visual analogue scale and the McGill Pain Questionnaire. Pain Relief was assessed using a five point verbal rating scale. Anxiety was assessed with the Spielberger short form State-Trait Anxiety Inventory.

Results: $\mathrm{IOI}$ patients were randomised and evaluated, 50 in the massage and $5 \mathrm{I}$ in the control group. There were no statistically significant differences between the groups at baseline interview. Patients in the massage but not the control group had significantly less pain compared to baseline immediately after and one hour post treatment. $95 \%$ confidence interval for the difference in mean pain reduction at one hour post treatment between the massage and control groups is $5.47 \mathrm{~mm}$ to $24.70 \mathrm{~mm}$. Patients in the massage but not the control group had a statistically significant reduction in anxiety compared to baseline immediately after and at I hour post treatment.

Conclusion: Massage is effective in the short term for chronic pain of moderate to severe intensity.

Trial Registration: [ISRCTN98406653] 


\section{Background}

Complementary therapies, such as massage, are increasingly used by health professionals to manage a wide range of symptoms, including pain [1]. A literature search revealed a paucity of well-designed randomised controlled trials to determine the effectiveness of massage for chronic pain. This study aims to determine whether a single session of massage reduces short term pain and anxiety in patients with chronic pain.

The use of complementary therapies is steadily growing, both in Europe and in the US [2-4]. Health care practitioners are increasingly incorporating such therapies within their care [5]. This increased used is despite lack of evidence of effectiveness [6]. Health professionals' desire to deliver best practice is coupled with government initiatives to ensure an evidence based approach to care. For example, in the UK the National Institute for Clinical Excellence and NHS Quality Improvement Scotland have been set up; in the US the Agency for Health Care Research \& Quality, and in Australia the National Institute for Clinical Studies all to try and ensure the health care delivered is based on what is known to be effective [7-10].

The holistic nature of nursing means massage is an attractive intervention for nurses to be able to offer patients. In addition to any direct therapeutic benefit, it allows nurses time with patients. It may be particularly relevant in settings where patients need immediate relief. Many nurses have undertaken courses in massage, however there is little robust evidence of its effectiveness. In today's evidence driven health care environment, if nurses are to justify the resources involved in training and delivery, they need evidence that massage is an effective treatment.

A literature search of Medline, EmBase, Cinahl and the Cochrane Controlled Trials Register and Cochrane Database of Systematic Reviews was undertaken, using free text and MeSH terms. Studies were sought which were randomised controlled trials, of manual massage therapies with or without oils, and which compared massage to at least one other treatment group (including usual care) in patients with chronic non malignant pain. Studies were excluded if they used non-manual massage or where massage was administered as part of a combination of therapies or was used for acute pain. Twenty eight studies were identified, of which eight met the criteria for inclusion.

After the RCT described in this paper was completed, a systematic review of massage for low back pain was published [11]. Outcomes considered in this review were pain, return to work, subjective change in symptoms and functional status. This superseded the literature review carried out prior to the conduct of the RCT reported in this paper. The systematic review concluded that massage might be beneficial for subacute and chronic non-specific low back pain, but that more studies were needed to confirm these conclusions [11]. Two of the RCTs included in review [11] found patients had less anxiety after massage $[12,13]$. Studies of chronic pain other than low back pain have found less anxiety and less pain [14-16].

In summary, despite the widespread and increasing use of massage for chronic pain, evidence of effectiveness is lacking, studies tend to be small and properly controlled studies are needed. An RCT to assess the effectiveness of massage for chronic pain was thus designed to add to the knowledge base in this area.

\section{Methods \\ Aim}

The aim of the study is to determine the effectiveness of a single session of nurse-administered massage for the short term relief of chronic non-malignant pain and anxiety.

\section{Design}

A randomised controlled trial design was utilised, in which the patients were assigned to two groups by simple block randomisation, using blocks of 10. Randomisation was carried out by use of a computerised random number generator and provided from a central office unconnected with the study. After obtaining informed consent from the patient, the allocation was obtained by telephone from the central office, thus allocation was concealed.

\section{Sample and Setting}

Patients aged 18 and over and attending a regional pain relief unit in England as in or out patients, who had experienced pain for three months or longer, whose pain was described as moderate or severe on the four point verbal rating pain intensity scale were eligible for the study. Patients were excluded if they did not speak English, did not consent or if they had taken any analgesics in the two hours prior to treatment. Outpatients were being followed up for the management of their chronic pain, and inpatients were admitted to the pain unit where patients stayed for one or more days in order to investigated ways of controlling their pain. The participants were a consecutive series of eligible patients and data collection took place between 1998 and 2000.

\section{Interventions}

The experimental group received a 15 minute manual massage of their back, neck and shoulders using sweet almond oil. The control group received a 15 minute visit to talk about pain clinic treatment. The treatment for both the experimental and control groups was carried out by two registered nurses qualified in massage (ITEC diploma). Each therapist (JM, KC) performed a sequence of the same massage techniques with the patients in the 
massage treatment group. This involved effleurage, petrissage and kneading techniques. For patients in the control group the therapist visited the patient for 15 minutes and encouraged them to talk about their pain and pain treatment. This is representative of usual care in this pain clinic, where health care staff talk to patients about their pain and its management, and no massage was performed for the control group. Patients in both groups were asked to try and complete at least one full hour after the intervention before requesting analgesics, but could request analgesics at any time after the intervention. If they received an analgesic, they were then excluded from any further follow-up assessments.

\section{Outcomes}

An independent nurse observer (DC), blind to the patients' treatment group, carried out assessments of the patient. These were carried out immediately before treatment (baseline), immediately after treatment (post treatment) and at 1, 2, 3 and 4 hours after treatment. The observer also recorded whether or not the patient had broken the blinding by inadvertently revealing their group allocation (for example, by referring to "my massage"). Once blinding was broken, it was considered unblinded for all subsequent assessments for that patient.

Pain intensity was assessed using a 0-100 mm visual analogue scale (VAS), the four point verbal rating pain intensity scale with descriptors of none $=0$, mild $=1$, moderate $=2$ and severe $=3$, both have been shown to be reliable, valid and appropriate for clinical use [17], and The McGill Pain Questionnaire Pain Rating Index [18]. Pain Relief was assessed using five point verbal rating scale with descriptors of none $=0$, slight $=1$, moderate $=2$, good $=3$ and complete relief $=4$. Anxiety was assessed with the six item Spielberger short form State-Trait Anxiety Inventory, [19]. At the end of the study period patients made an overall rating of the study treatment using a five point scale (poor $=0$, fair $=1$, good $=2$, very good $=3$ or excellent $=$ 4 ). They also rated whether they had achieved 50\% pain relief [20].

\section{Sample Size}

The sample size was calculated for comparing mean difference in pain score and for the study to have a power of $90 \%$ [21]. The results of a study of pain relief through relaxation in elderly hip fracture patients suggests that when using a pain scale rating pain from 1 to 10 that the standard deviation for patients with chronic pain on this scale is 2.5 [22]. On this scale a mean difference of 1.5 in pain scores between the treatment groups could be considered clinically worthwhile. Since in the current study a $100 \mathrm{~mm}$ VAS pain scale will be used a standard deviation of $25 \mathrm{~mm}$ and a mean difference of $15 \mathrm{~mm}$ are consistent with the earlier study [22]. With type I error set at 0.05 , then the study would require 60 patients per group. If a difference as large as $20 \mathrm{~mm}$ between the pain scores was attained this could be demonstrated with 34 patients per group. In the current study it was decided, based on the difference found in the previous study of elderly hip fracture patients, recruit 60 to each group: a total of 120 patients.

\section{Ethical considerations}

The study received ethical approval from the Local Research Ethics Committee (Study Code NAPREC 97.053). All participants recruited to the study had received a verbal explanation of the study and were provided with a written information sheet. All potential participants had at least 24 hours between receiving information and deciding whether or not they wished to take part in the study. All participants gave written consent.

\section{Data analysis}

In the analysis baseline pain and anxiety scores are compared for the two treatment groups using t-tests. To investigate the treatment effect, for each patient their pain scores after treatment are compared to their baseline pain score (pre-treatment). The mean difference in change in pain score for the two treatment groups is compared using a 2 sample t-test. Similarly changes in anxiety between baseline and post treatment are compared for the two groups sample t-test. Box plots are used to show graphically the differences between groups. The box includes the $25^{\text {th }}, 50^{\text {th }}$ and $75^{\text {th }}$ percentiles; the whiskers indicate the range of the data, with asterisks indicating outliers. Statistical significance was set at the $5 \%$ level. The data were analysed using SPSS version 12 and MINITAB version 13 .

\section{Results}

In total 103 patients participated in the study of whom 52 were randomly allocated to the massage group and 51 to the control group. Two patients allocated to the massage group withdrew at baseline, one because they received morphine just prior to starting the study and the other because they were unable to understand the assessment scales, thus the analysis reports results for the 101 patients who completed the baseline assessments. The patients were aged between 21 and 81 years, with mean age 53.4 years (SD 13.3 years) and 58.4\% were female. The mean time that the patients had experienced chronic pain was 10.4 years (SD 8.94 years). $87 \%$ of the patients had a diagnosis which included back pain and $58 \%$ had more than one pain site. At baseline, 60.4\% had moderate and $39.6 \%$ had severe pain as recorded on the verbal rating scale.

Figure 1 shows the number of patients still taking part in the study at each assessment point. After the first hour the 


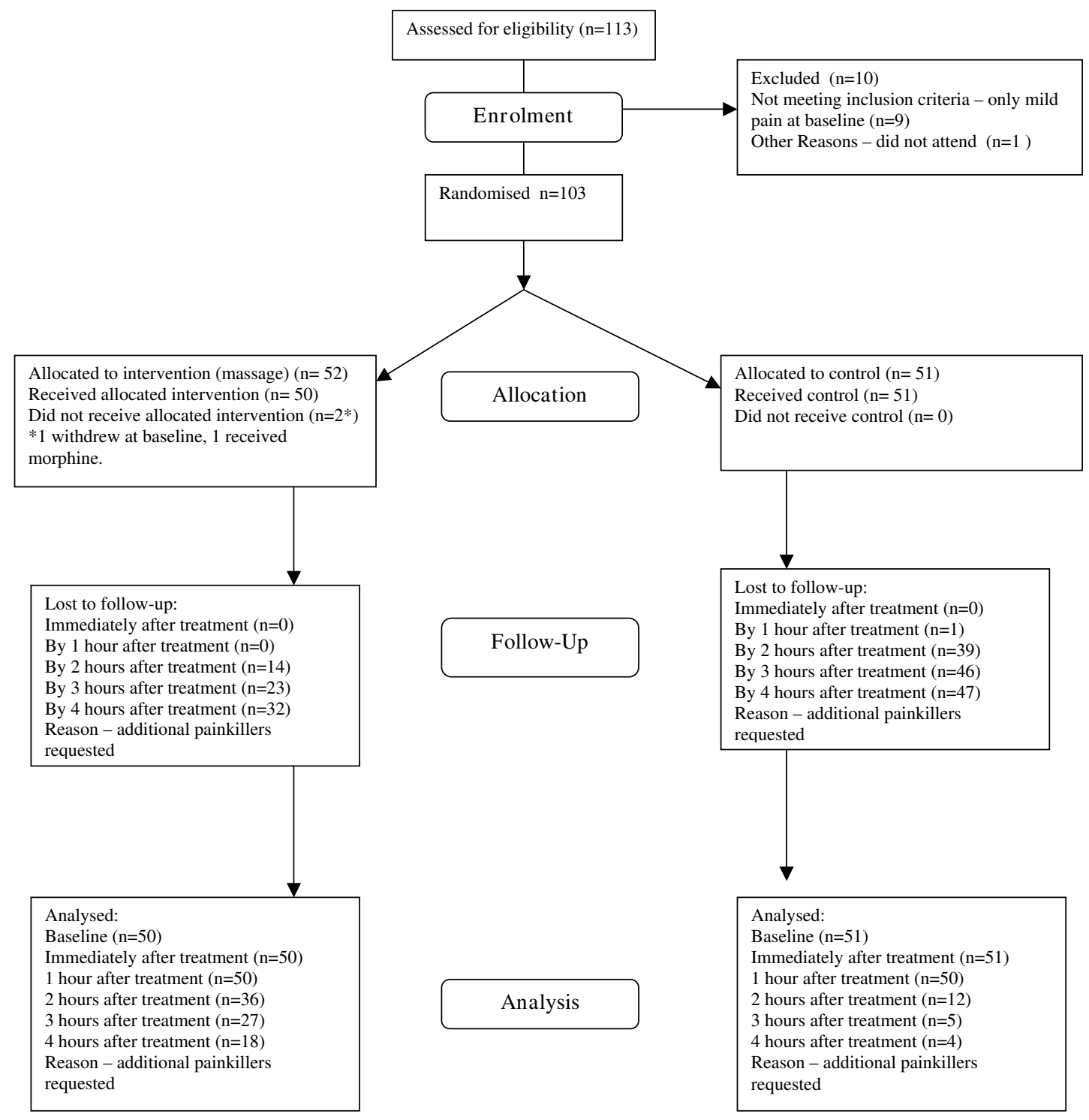

Figure I

Participant Flow at each stage of study.

drop out from both groups, but particularly from the control group was rapid. By the 2 hour post-treatment assessment only $23 \%$ of patients in the control group remained in the study and by the 3 hour assessment only $10 \%$ of the control group were available for assessment. In comparison for the massage group $72 \%$ of patients remained in the study at 2 hours post-treatment, 54\% at 3 hours and $36 \%$ at 4 hours post treatment. Because of the very high withdrawal rate at 2, 3 and 4 hours after treatment, the results from these time periods are impossible to interpret and are therefore not presented.
The assessment of the patients at all time points was by an observer who was blind to the treatment that the patient received (DC). Occasionally the patient would break the blinding by comments that they made to the observer. For 89 of the 100 patients in which a record of blinding was made, the observer remained blind throughout the assessment, so blinding was maintained in $89 \%$ of patients.

The demographic characteristics and baseline scores for the massage and control groups are compared in Table 1. Comparisons between massage and control groups were tested using chi-squared or two sample t-tests as appropri- 
Table I: Comparison of the characteristics of the massage and control groups at baseline (pre-treatment)

\begin{tabular}{|c|c|c|c|}
\hline Characteristic & Massage group & Control Group & p-value \\
\hline Number in group & 50 & 51 & \\
\hline Gender (male:female) & $22: 28$ & $20: 31$ & 0.626 NS \\
\hline Age in years Mean (SD) & $51.5(13.4)$ & $55.2(12.9)$ & $0.171 \mathrm{NS}$ \\
\hline Duration of pain in years. Mean (SD) & $9.86(7.47)$ & $11.0(10.2)$ & $0.540 \mathrm{NS}$ \\
\hline Therapist (A:B) & $27: 23$ & 27:24 & $0.915 \mathrm{NS}$ \\
\hline Pain VAS. Range 0-100. Mean (SD) & $57.7(18.0)$ & $62.3(16.6)$ & $0.200 \mathrm{NS}$ \\
\hline McGill Pain Q'aire Pain Rating Index Range 0-78 Mean (SD) & $27.3(11.5)$ & $25.1(14.4)$ & $0.390 \mathrm{NS}$ \\
\hline Spielberger SF STAI Range 6-24 Mean (SD) & $13.3(4.16)$ & $12.0(4.15)$ & $0.139 \mathrm{NS}$ \\
\hline
\end{tabular}

ate. There are no significant differences in the age, gender mix or duration of pain for the two treatment groups.

The pain verbal rating scale scores are "moderate" or "severe" for all patients, with $40 \%$ of the massage group and $39 \%$ of the control group recording severe pain at baseline. The similarity of the distribution of pain scores between the two groups is shown in the boxplot in Figure 2.

Comparisons post-treatment of pain VAS scores are shown in Figure 3 and Table 2. Figure 3 illustrates that the $95 \%$ confidence intervals for mean pain VAS for the massage and control groups overlap at baseline, the means are not significantly different. However, the confidence intervals are clearly distinct both immediately post treatment and at 1 hour post treatment, consistent with the massage group having significantly lower mean pain VAS. For the control group mean pain VAS for those who continue beyond 1 hour (the minority) is 36.4, but mean pain VAS for those in the control group who withdraw at 1 hour (the majority) is 74.7, a significantly higher mean ( $\mathrm{p}<$ $0.001)$.

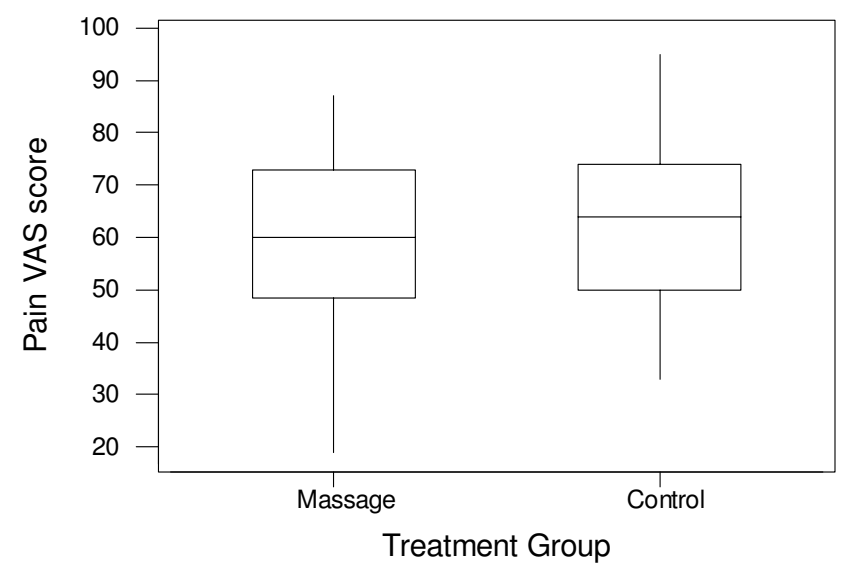

Figure 2

Baseline (pre-treatment) pain VAS scores for the massage and control groups.
Table 2 compares the baseline score to that immediately post treatment, the massage group experience a statistically significant $(\mathrm{p}<0.001$ using paired t-test) mean reduction in pain of $16.7 \mathrm{~mm}$ (SD 21.2). For the control group the mean change in pain score is $-0.04 \mathrm{~mm}$ (SD 16.0) which is not significant ( $\mathrm{p}=0.985$ using paired $\mathrm{t}$ test). For those in the massage group there is a significantly greater reduction in pain score both immediately post treatment and at 1 hour post treatment than in the control group. The 95\% confidence interval for the difference in mean pain reduction at one hour post treatment between the massage and control groups is $5.47 \mathrm{~mm}$ to $24.70 \mathrm{~mm}$, that is the massage group can expect on average to benefit by between $5.47 \mathrm{~mm}$ and $24.70 \mathrm{~mm}$ greater reduction than the control group up to one hour post treatment.

Figure 4 illustrates the reduction in pain VAS score for the massage group and the negligible change in pain VAS score for the majority of members of the control group. For both groups the median is central in the box of the boxplot, thus supporting the assumption that the data is normally distributed and that a t-test can be used to compare these changes.

The results from the four point verbal rating pain, the four point pain distress scale and the McGill Pain Questionnaire produce the same findings as the pain VAS scale. That is, statistically significant differences between massage and control groups immediately and one hour post treatment.

An example of these similarities is shown in comparisons of McGill Pain Questionnaire scores from baseline to immediately post treatment. The massage group experience a statistically significant $(\mathrm{p}<0.001$ using paired $\mathrm{t}-$ test) mean reduction in McGill pain score of 11.5 (SD 9.93). For the control group the mean change in McGill pain score is 1.22 (SD 7.16) which is not statistically significant $(\mathrm{p}=0.237$ using paired $\mathrm{t}$-test). 
Table 2: Comparison of massage group and control group for both pain VAS scores and changes in pain VAS score from baseline, at post treatment assessments*.

\begin{tabular}{|c|c|c|c|c|c|c|c|}
\hline \multirow[t]{2}{*}{ Time point } & \multicolumn{3}{|c|}{ Massage group } & \multicolumn{3}{|c|}{ Control group } & \multirow[t]{2}{*}{ p-value ( 2 sample t-test) } \\
\hline & Mean & SD & $\mathrm{N} \#$ & Mean & SD & $\mathrm{N} \#$ & \\
\hline Baseline score & 57.7 & 18.0 & 49 & 62.3 & 16.6 & 47 & $0.200 \mathrm{NS}$ \\
\hline Immediately post treatment score & 41.1 & 20.2 & 49 & 62.8 & 20.9 & 47 & \\
\hline Change from baseline & 16.7 & 21.2 & 48 & -0.04 & 16.0 & 45 & 0.000 \\
\hline I hour post treatment score & 44.8 & 23.5 & 47 & 64.9 & 26.7 & 43 & \\
\hline Change from baseline & 12.4 & 21.3 & 47 & -2.66 & 24.0 & 41 & 0.002 \\
\hline
\end{tabular}

\footnotetext{
* Note that at each time point adding the change from baseline scores to the post treatment scores will not necessarily equal the baseline scores, because some patients have dropped out after the baseline

$\mathrm{SD}=$ Standard Deviation

NS = Not significant

\# the table has some missing data on VAS scores at baseline, but data available on other outcomes. One participant in the massage group and 3 in control group did not complete VAS pain scores, and thus were not included in the later comparisons to baseline.
}

Table 3 showed, using a chi-squared test, a significant association between treatment group and whether the patient gets $50 \%$ pain relief, with only one person in the control group but $18 / 31$ and $18 / 32$ patients in the massage group reporting $50 \%$ pain relief immediately post and 1 hour post treatment.

Table 4 illustrates results from the Spielberger short-form anxiety scale. It shows that comparing the baseline score to that immediately post treatment, the massage group experience a statistically significant $(\mathrm{p}<0.001$ using paired t-test) mean reduction in STAI score of 3.57 (SD 3.02 ). For the control group the mean change in STAI score is 0.00 (SD 3.39) which is not statistically significant ( $\mathrm{p}=1.00$ using paired t-test). For those in the massage group there is a statistically significantly greater reduction

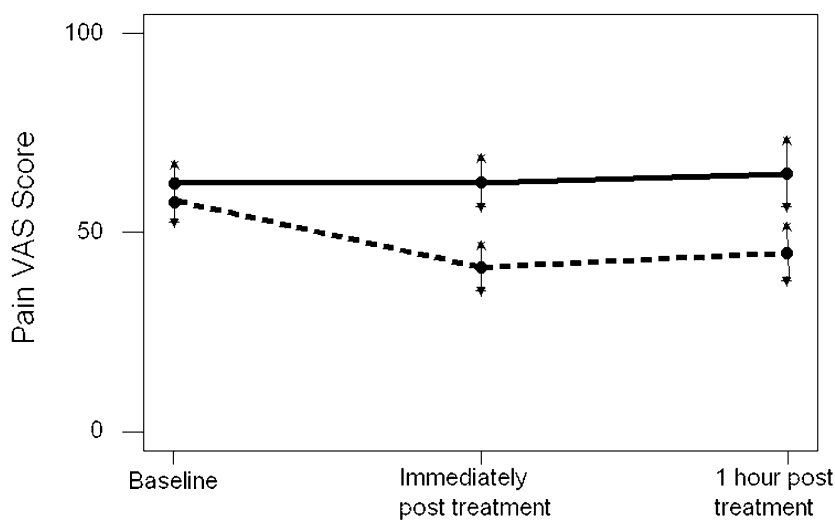

Figure 3

Mean and $95 \%$ confidence interval for the mean pain VAS scores for the massage group (- . . - ) and the control group $(\longrightarrow$ ) at three time points. in anxiety score both immediately post treatment and at 1 hour post treatment than in the control group. The 95\% confidence interval for the difference in mean anxiety score reduction at one hour post treatment between the massage and control groups is 1.67 to 4.36 that is the massage group can expect on average to benefit by between 1.67 and 4.36 greater reduction in anxiety score than the control group up to one hour post treatment.

At the final assessment for the patient, either at 4 hours post treatment or at the point that they requested an analgesic and thus withdrew from the study the patient was asked to assess whether the treatment they had received

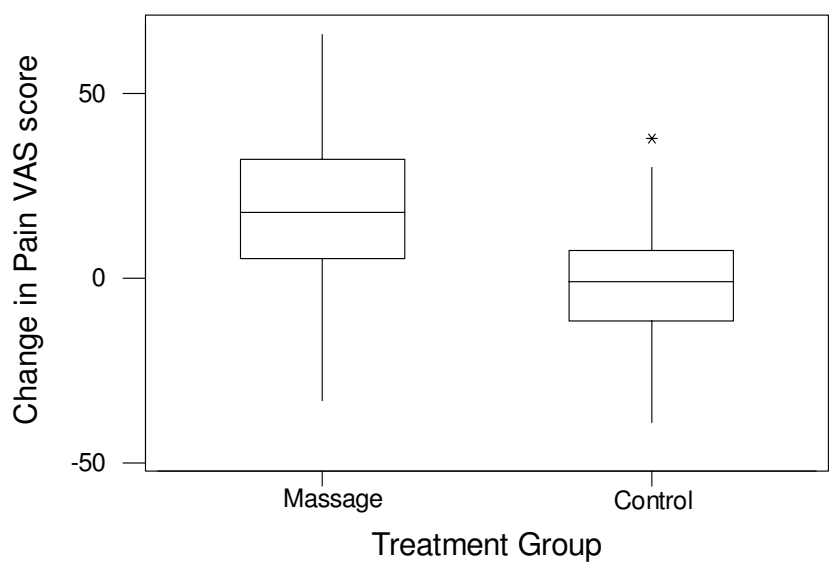

Figure 4

Change in pain VAS score between baseline and immediately post treatment for both the massage group and the control group. The change is calculated as baseline - post-treatment, so positive values indicate pain has been reduced by treatment. 
Table 3: Comparison of massage group and control group for $\mathbf{5 0 \%}$ pain relief at post treatment assessment.

\begin{tabular}{lcccc}
\hline Time point & Massage group 50\% pain relief & Control group 50\% pain relief & p-value \\
\cline { 2 - 5 } & Yes & No & Yes & 51 \\
\hline $\begin{array}{l}\text { Immediately post treatment } \\
\begin{array}{l}\text { Change from baseline } \\
\text { I hour post treatment } \\
\text { change from baseline }\end{array}\end{array}$ & 18 & 31 & 0 & 0.000 \\
\hline
\end{tabular}

was poor, fair, good, very good or excellent. In the massage group, 34 rated the treatment as good, very good or excellent, 12 as fair and 4 as poor. In the control group, 4 rated it as good, very good or excellent, 14 as fair and 33 as poor. A chi-squared test for the patients' assessment of the treatment demonstrates that those receiving the massage rate this treatment statistically significantly better than the control group $\left(\mathrm{X}^{2}=46.6, \mathrm{df}=2\right.$, $\left.\mathrm{p}<0.001\right)$.

At the final assessment the patient was asked whether they would like to have the treatment again. A significantly higher proportion of those in the massage group $\left(\mathrm{X}^{2}=\right.$ $24.4, \mathrm{df}=1, \mathrm{p}<0.001)$ said they would like the treatment again. Of the 49 patients in the massage group who were asked this question all $49(100 \%)$ said yes they would like the treatment again. Of the 42 patients in the control group asked this question, 25 (60\%) said yes they would like the treatment again.

\section{Discussion}

This study showed that, compared to baseline, massage reduced pain and anxiety for up to one hour. There were no such differences for the control group. This suggests that massage could be a useful short term intervention, to reduce both pain and anxiety. Although an hour's pain relief after a massage may seem a short duration, this could be very worthwhile if, for example, the patient is anxious or fearful about a procedure they are about to undergo, or they are waiting for an analgesic to take effect, or to give them some short term respite from pain during the day and thus a sense of a degree of control over the pain.

The results showed that these patients with moderate to severe chronic pain are used to taking analgesics, with $77 \%$ of patients in the control group dropping out to take an analgesic after one hour post intervention, and 92\% control patients had dropped out by 4 hours post intervention.

One of the problems of demonstrating any statistically significant effect of massage over time was the large drop out rate. Once the patient had taken an analgesic, the effects due to the massage could no longer be reliably elicited and they had to be excluded. The differential drop out rate between the groups is interesting. At 2 hours post treatment $72 \%$ of patients having massage compared to only $23 \%$ of those in the control group remained in the study. At 3 hours post treatment 53\% of massage patients compared to only $10 \%$ of control patients remained. At the final assessment after 4 hours, over a third (36\%) of massage patients remained compared to only $8 \%$ of those in the control group. This gives at least an indication that because patients who dropped out did so because they requested an analgesic, those in the massage group who stayed in the study did so because they had less pain.

The study had aimed to recruit 120 patients, 60 in each group. In the event, 101 were included in the study. This was based on a previous study of relaxation in hip fracture

Table 4: Comparison of massage group and control group for both Spielberger STAl scores and changes in STAI score from baseline, at post treatment assessments.

\begin{tabular}{|c|c|c|c|c|c|c|c|}
\hline \multirow[t]{2}{*}{ Time point } & \multicolumn{3}{|c|}{ Massage group } & \multicolumn{3}{|c|}{ Control group } & \multirow[t]{2}{*}{ p-value } \\
\hline & Mean & sd & $\mathrm{n}$ & Mean & Sd & $N$ & \\
\hline Baseline score & 13.3 & 4.16 & 50 & 12.0 & 4.15 & 47 & $0.139 \mathrm{NS}$ \\
\hline Immediately post treatment score & 9.72 & 3.43 & 47 & 12.2 & 5.15 & 47 & \\
\hline Change from baseline & 3.57 & 3.02 & 47 & 0.00 & 3.39 & 44 & 0.000 \\
\hline I hour post treatment score & 10.5 & 3.90 & 50 & 12.8 & 5.06 & 47 & \\
\hline Change from baseline & 2.74 & 3.10 & 50 & -0.28 & 3.43 & 43 & 0.000 \\
\hline
\end{tabular}


patients which had a standard deviation of $25 \mathrm{~mm}$ and a mean difference of $15 \mathrm{~mm}$ [18]. If we take the actual VAS pain scores comparing baseline to immediately post treatment, there is a mean difference of $16 \mathrm{~mm}$ and a standard deviation of $21 \mathrm{~mm}$. For a mean difference and standard deviation of this size a sample size of 45 per group, gives power of $95 \%$. So, looking at this outcome, the study is adequately powered.

The extent of a statistically significant reduction of pain and whether it is clinically significant is important to consider. Compared to baseline, those in the massage group had a mean reduction in pain of $16.7 \mathrm{~mm}$ on a $0-100$ scale immediately after treatment. If $50 \%$ pain relief is taken as clinically important, $36 \%$ of the massage group reported at least this level of relief immediately post treatment, compared to $0 \%$ of the control group. This provides some evidence that the massage can have quite a large effect in just over a third of patients. Although a benefit of reduced pain for one hour may seem a limited effect, it does provide something of a break from pain.

It is then a clinical question whether the 15 minute investment of time in doing the massage is worth the benefits outlined in the paper. When patients either completed the study or withdrew, $68 \%$ of massage patients compared to only $8 \%$ of control patients said the intervention had been good, very good or excellent, so it would seem over two-thirds of patients did find the treatment beneficial. This could be one area where carers may be able to take on this role, although anecdotally, we are aware that some clinicians may be reluctant to make this suggestion to carers, fearing litigation if there are any adverse effects. Health professionals wishing to integrate massage into their practice need to consider professional training, and the requirements of the regulatory bodies of their own country. For example, in the UK, the Royal College of Nursing produced guidance on integrating complementary therapies into clinical care [23]. It would also be sensible to liaise with the appropriate committees within their own hospital or community setting regarding the level of training required to practice (for example, the formal structures addressing risk management, quality assurance and professional development).

This study adds to the international knowledge base about the effectiveness of massage for chronic pain. It has demonstrated that massage can produce short term reductions in pain and anxiety, and improvements in pain relief which are valued by patients. These are important potential benefits for people in whom the management of pain is often a challenge.

\section{Conclusion}

Massage is effective in the short term for chronic pain of moderate to severe intensity, and has a small anxiety reducing effect. It could be a useful addition to techniques offered to patients as part of their care. Nurses are well placed to be trained in and to deliver massage. More research is needed to explore the benefits of repeated treatments of massage in patients with chronic pain.

\section{Competing interests}

The authors declare that they have no competing interests.

\section{Authors' contributions}

KS conceived the study and participated in its design and coordination and drafted the manuscript. NC participated in the design, conducted the statistical analysis and helped to draft the manuscript, JM and $\mathrm{KC}$ were involved in the data collection, delivering the intervention and helped draft the manuscript, DC participated in the design of the study and the data collection and helped draft the manuscript. All authors read and approved the final manuscript.

\section{Acknowledgements}

This study was funded by the Oxfordshire Health Services Research Fund. The funder was not involved in the design, conduct or interpretation of the study. Thank-you to all patients and staff involved in this study for their time and support.

\section{References}

I. Rankin-Box D: Therapies in practice: a survey assessing nurses' use of complementary therapies. Complementary Therapies in Nursing \& Midwifery 1997, 3:92-98.

2. Ernst $E$, White $A$ : The $B B C$ survey of complementary medicine use in the UK. Complementary Therapies in Medicine 2000, 8:32-36.

3. Eisenberg DM, Davis RB, Ettner SL, Appel S, Wilkey S, Rompay MV, Kessler RC: Trends in alternative medicine use in the United States, 1990-1997. Results of a follow-up national survey. Journal of the American Medical Association 1998, 280:1569-1575.

4. Wiesenger GF, Quittan M, Ebenbichler G, Kaider A, Fialka V: Benefit and costs of passive modalities in back pain outpatients: a descriptive study. European Journal of Physical Medicine Rehabilitation 1977, 7:182-186.

5. Mills S, Budd S: Professional organisation of complementary and alternative medicine in the United Kingdom 2000. A second report to the Department of Health Centre for Complementary Health Studies, University of Exeter; 2000.

6. White House Commission: White House Commission on Complementary and Alternative Medicine Policy. Final Report 2002 [http://www.whc camp.hhs.gov/finalreport pdf.html]. Accessed $8^{\text {th }}$ June 2007

7. National Institute for Clinical Excellence [http:// www.nice.org.uk/]. Accessed 8th June 2007

8. NHS Quality Improvement Scotland (NHS QIS) [http:// www.nhshealthquality.org/]. Accessed 8th June 2007

9. Agency for Health Care Research \& Quality [http:// www.ahrq.gov/]. Accessed 8th June 2007

10. National Institute of Clinical Studies [http://www.nicsl.com.au/ ]. Accessed $8^{\text {th }}$ June 2007

II. Furlan AD, Brosseau L, Imamura M, Irvin E: Massage for low-back pain. Cochrane Database of Systematic Reviews 2002:CD001929.

12. Preyde M: Effectiveness of massage therapy for subacute lowback pain: a randomized controlled trial. Canadian Medical Association Journal 2000, 162(13): |8|5-1820.

13. Hernandez-Reif M, Filed T, Krasnegor J, Theakston H: Lower back pain is reduced and range of motion increased after massage therapy. International Journal of Neuroscience 1 06: I31-145. 
14. Sunshine W, Field T, Quintino O, Fierro K, Kuhn C, Burman I, Schanberg S: Fibromyalgia benefits from massage therapy and transcutaneous electrical stimulation. Journal of Clinical Rheumatology 1996, 2: 18-22.

15. Field T, Peck M, Krugman S, Tuchel T, Schanberg S, Kuhn C, Burman I: Burn injuries benefit from massage therapy. Journal of Burn Care and Rehabilitation 1998, 19:24I-244.

16. Field T, Hernandez-Reif M, Seligman S, Krasnegor J, Sunshine W: Juvenile rheumatoid arthritis: benefits from massage therapy. Journal of Pediatric Psychology 1997, 22:607-617.

17. Williamson A, Hoggart B: Pain: a review of three commonly used pain rating scales. Journal of Clinical Nursing 2005, I 4(7):798-804.

18. Melzack R: The McGill Pain Questionnaire: Major properties and scoring methods. Pain 1975, I:277-299.

19. Marteau TM, Bekker H: The development of a six-item shortform of the state scale of the Spielberger State-Trait Anxiety Inventory (STAI). British Journal of Clinical Psychology 1992, 3I:30I-306.

20. McQuay HJ, Moore RA, Eccleston C, Morely S, Williams AC: Systematic review of outpatient servies for chronic pain control. Health Technol Assess 1997, I(6): I-I35.

21. Campbell MJ, Machin D: Medical Statistics A common sense approach 3rd edition. Chichester, UK: John Wiley \& Sons Ltd; 1999.

22. Ceccio CM: Postoperative pain relief through relaxation in elderly patients with fractured hips. Orthopaedic Nursing 1984, 3:II-19.

23. Royal College of Nursing: Complementary therapies in nursing, midwifery and health visiting practice. $R C N$ guidance on integrating complementary therapies into clinical care RCN, London; 2003.

\section{Pre-publication history}

The pre-publication history for this paper can be accessed here:

http://www.biomedcentral.com/1472-6955/7/10/prepub

Publish with Biomed Central and every scientist can read your work free of charge

"BioMed Central will be the most significant development for disseminating the results of biomedical research in our lifetime. "

Sir Paul Nurse, Cancer Research UK

Your research papers will be:

- available free of charge to the entire biomedical community

- peer reviewed and published immediately upon acceptance

- cited in PubMed and archived on PubMed Central

- yours - you keep the copyright 